\title{
Social consequences and mental health outcomes of living in high-rise residential buildings and the influence of planning, urban design and architectural decisions: a systematic review
}

\begin{abstract}
Different types of high-rise residential buildings have proliferated in different countries at least since the 1940s, for a range of reasons. This paper aims to provide an overview of the current state of evidence on how planning, urban design and architectural aspects of high-rise residential buildings may influence social well-being and mental health. A systematic review following the PRISMA guidelines was conducted. Searches for peer-reviewed papers were conducted in MEDLINE, Embase, Psyclnfo, Scopus, SciELO, and Web of Science; 4,100 papers were assessed. 23 empirical studies published between 1971 and 2016 were included. The review found that house type, floor level, as well as spaces intrinsic to high-rise residential buildings (e.g. shared stairwells) are associated with social well-being and mental health. However, conceptual gaps and methodological inconsistencies still characterise most of the research in this field. We expect that research about and policy attention to this subject may intensify due to its strategic relevance in the face of global challenges such as increasing urbanization and loneliness. This paper concludes by highlighting a number of recommendations for future research.
\end{abstract}

Keywords: high-rise housing; residential building; mental health; social well-being; urban planning; physical design

\section{Highlights}

1. House type, floor level, and spaces intrinsic to high-rises are associated with social well-being and mental health.

2. Most research shows methodological problems and lack of conceptual consensus.

3. Cross-national research and studies in cities in the Global South are needed.

4. There is a lack of studies on positive mental health.

5. Mediators, moderators and confounding variables need to be studied conjointly. 


\section{Introduction}

Housing has long been associated with health. The World Health Organization (WHO) has considered housing a determinant of health from its formation in 1948 (Howden-Chapman et al., 2017). Although there is not a consensual cross-disciplinary definition for health, since the WHO's $(2014$, p.1) well-known definition of health as "[...] a state of complete physical, mental and social well-being and not merely the absence of disease of infirmity", social well-being, also known as social health, and mental health have been understood as essential and inter-related aspects of health.

Different definitions and indicators of social well-being and mental health permeate the literature because they tend to be conceptualized according to research aims (Hashemi et al., 2016) and, on the other hand, these are also culture-related. For the purposes of this review, social well-being is defined as "the appraisal of one's circumstance and functioning in society" (Keyes 1998, p.122), and good mental health as "[...] a state of well-being in which the individual realizes his or her own abilities, can cope with the normal stresses of life, can work productively and fruitfully, and is able to make a contribution to his or her community" (WHO 2007, p.1).

United Nations have directed efforts to promote social well-being and mental health because these highly neglected aspects of health are critical to the achievement of WHO's 2030 Sustainable Development Goals (United Nations, 2018). Although the health effects of living in high-rise residential building are still to be fully understood, this house type has been a common solution for accommodating population growth across the globe. The report carried out by the Council on Tall Buildings and Urban Habitat (CTBUH) in 2018 shows that there was a 464\% increase in high-rise buildings with total height over 200m in the world from the year 2000 (CTBUH, 2019).

Like health, high-rise building, as health and its aspects, has no internationally accepted definition (Al-Kodmany, 2018). This housing type includes multi-story buildings that differ in many aspects such as in their height, primary use (e.g. office, residential, mixed-use), architectural design, scale, meaning and market position. Rapid urbanization and the need to control urban sprawl, whose cost is over 1 US\$ trillion annually (Litman, 2015), are not the only factors that have driven the construction of high-rise residential buildings. Other forces include increases in land prices, massive migration from rural to urban areas, global competition, human aspiration, symbolism, and ego (Al-Kodmany, 2018).

In addition to the increasing demand for designing and building high-rise residential buildings, there has been an interest in retrofitting those that have been associated with social isolation, crime, negative image, poor indoor air quality, and other problems, as the case of Amsterdam's Bilmermeer high-rise illustrates (Helleman \& Wassenberg, 2004).

Mental health disorders have a bi-directional relationship with social well-being and accounted for $57 \%$ of disability-adjusted life years, according to the Global Burden of Disease Study 2010 (Whiteford et al., 2015). Awareness of that; the rapid growth 
in the height and numbers of high-rises; the long life cycle of this building type, the demand for upgrading aging high-rise residential buildings; the value of residential spaces to people; and the longstanding associations of housing with health call for a systematization of what is known about the inter-relationships between high-rise residential building, social well-being and mental health.

To our knowledge, however, no systematic review of the evidence has been conducted on this topic, although other types of reviews have been carried out on living environments, social well-being and/or mental health (Blair et al., 2014; Clark et al., 2007; Diez et al., 2010; Evans, 2003; Evans et al., 2003; Gong et al., 2016; Julien et al., 2012; Mair et al., 2008; Mazumdar et al., 2018; Moore et al., 2018; Mueller, 1981; Renalds et al., 2010; Rautio et al., 2017; Truong \& Ma, 2006).

From all these earlier reviews, only one, a critical review carried out 15 years ago by Evans et al. (2003), focused on aspects of high-rise residential buildings (house type, floor level and housing quality) and mental health. Evans and his colleagues (2003) concluded that housing does influence residents' mental health and discussed the importance of taking into account moderating and mediating constructs as well as the role of psychosocial processes, which for the purposes of this research are under the umbrella of social well-being, as mediators variables (Fig. 1).

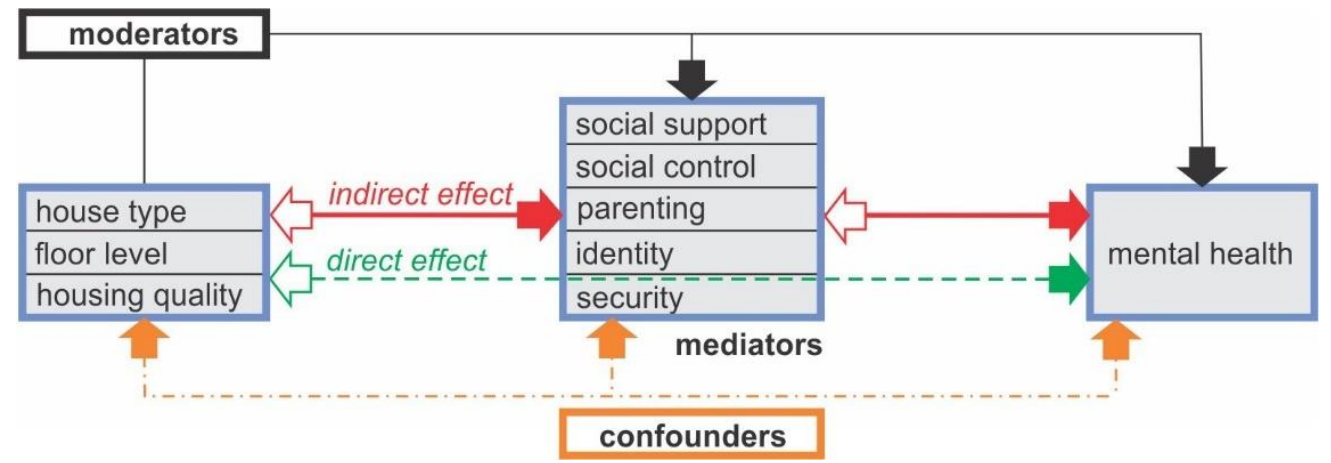

Fig. 1. Factors that influence the inter-relationship between high-rise residential building and mental health.

With these policy priorities and gap in research, the authors build on past efforts (notably Evans et al., 2003) to provide an overview of the current state of evidence on the inter-relationships between physical and spatial aspects of high-rise residential buildings, social well-being and/or mental health. As part of an attempt to bring a range of technical expertise and viewpoints, this review was conducted by a team covering a wide range of disciplines, including architecture, planning, urban design, economics, public health and epidemiology.

We hope that the findings of this review will: (i) help policy makers, urban planners, urban designers, architects, landscape architects and public health professionals to take evidence-based decisions that will contribute towards the enhancement of social well-being and mental health among those who live in high-rise residential buildings, and (ii) promote high-quality research on a topic that is key to the quality of life of a large proportion of the global population in cities.

\section{Methods}




\subsection{Literature search}

We performed a systematic review of studies investigating the influence of living in high-rise buildings on social consequences and/or mental health outcomes (excluding psychotic illness), following the PRISMA guidelines (Liberati et al., 2009). A systematic literature review is an approach regularly used in the public health field as an attempt to reduce biases in the process of compiling the available evidence to respond to a specific research question. It therefore involves a pre-specified, specific research question that results in an extensive search of several databases using both free text and thesaurus terms, combined using Boolean operators; selection of relevant studies based on pre-specified eligibility criteria; extraction of relevant information within each study under a pre-specified extraction protocol; and the assessment of the quality and risk of bias of the available evidence identified. Unlike scoping reviews, another common type of knowledge synthesis, systematic reviews are not intended to map evidence on a topic - e.g. housing, social connectedness, and mental health - so as to identify main concepts, theories, sources, and knowledge gaps (Tricco et al., 2018).

MEDLINE, Embase, PsycINFO, Scopus, SciELO, and Web of Science were searched between August and October 2016. The full search strategy for each database is available as Supplementary Material 1.We searched in title, abstract, keywords, and subject descriptors using combinations of terms in English related to: high-rise residential buildings (e.g. high-rise, flat, apartment, social housing, collective housing, housing, built environment, high density), plus social outcomes / psychosocial processes (e.g. social support, community network, social isolation, loneliness, social capital, social network, social inclusion, social interaction, sense of community, cohesion), and/or mental health (e.g. agoraphobia, depression, neurotic disorder, psychological stress, anxiety, mood disorder, depressive disorder, mental health, well-being). Duplicate records were removed using EndNote ${ }^{\mathrm{TM}}$ 7.7.1 (Thomson Reuters, Carlsbad, California, United States).

\subsection{Study selection criteria and process}

To be included, studies had to be carried out within urban areas; we had no limits on geographic location. Participants had to be non-institutionalized people living in high-rise buildings, but no limits on any demographic or social attribute were set. Initially we sought papers that investigated all three variables in a single study, given their known associations, but the lack of such reports led us to also investigate the separate associations of high-rise residential building and social well-being or mental health. Therefore, publication content had to include associations between high-rise residential buildings and social well-being and/or mental health. Papers that reported only on the associations between neighbourhoods containing high-rise buildings and social well-being and/or mental health outcomes were excluded. No limits were set for publication date, language, or study design. Theoretical papers and reviews were not included. 
We performed a two-phase selection process. First, we assessed documents based on title and abstract. Then we retrieved and reviewed the full text of filtered-in papers. All authors participated in both phases, grouped in pairs from different disciplinary backgrounds to minimise associated bias. In each phase, each pair received a share of documents to assess; each member independently assessed fulltext articles to check their eligibility. Disagreements between the two reviewers about which studies to include were resolved by discussion and, if not resolved, by involving a third reviewer. We retrieved 4,945 records from the electronic database search, from which 4,100 were assessed after duplicates were excluded. 23 studies met the eligibility criteria (Fig. 2).

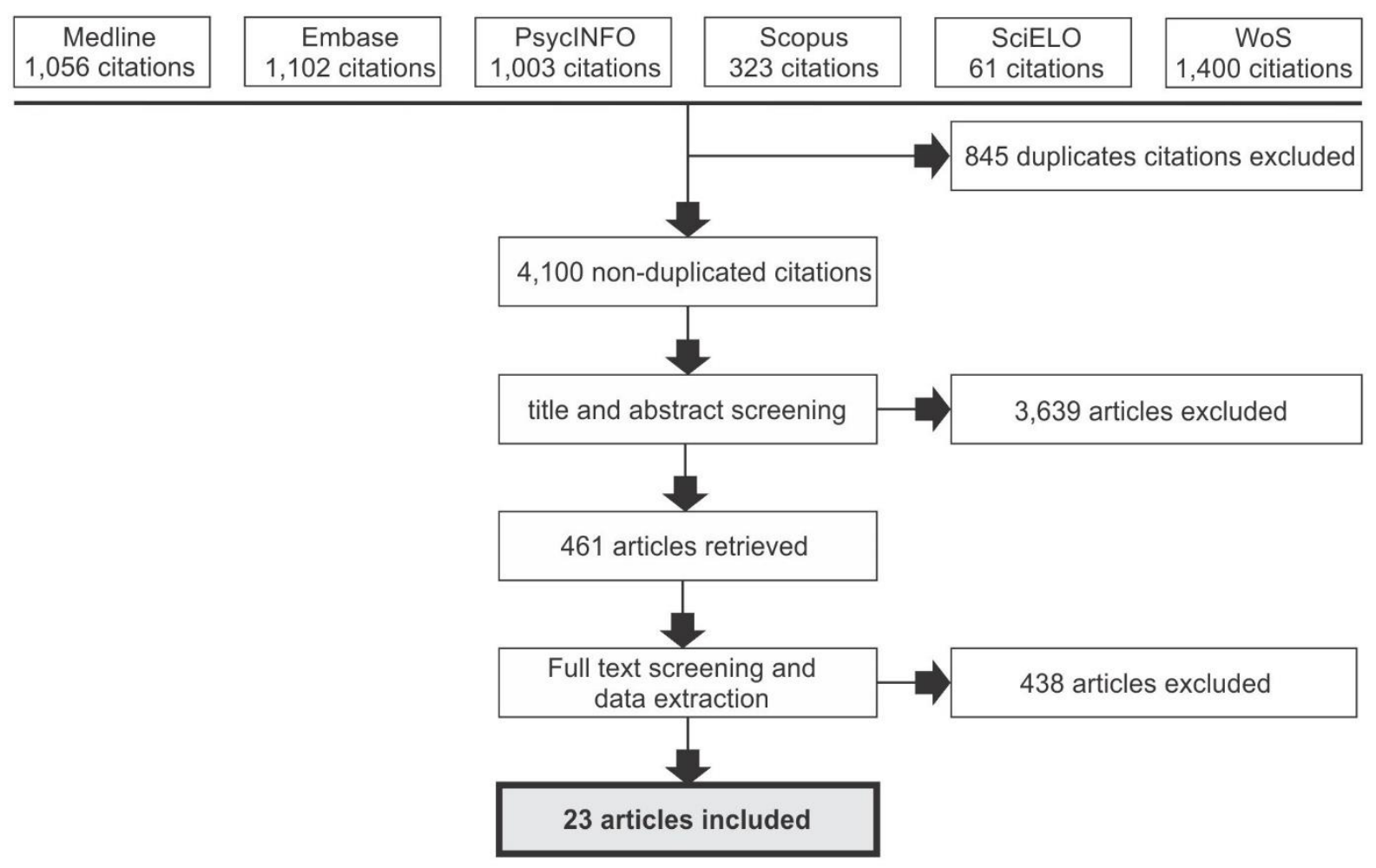

Fig. 2. Flowchart of study selection.

\subsection{Data extraction}

We independently extracted data using a collection form pretested through a pilot review on a sample of papers. A second reviewer revised the data extraction, and a third reviewer resolved any disagreements. For each study, we retrieved the following information: publication attributes (title, authors, year of publication, and main scope of the source); study objective, setting, and design; sample size and attributes (both of buildings and people); data collection and analysis methods; concepts and operationalisation regarding high-rise housing, social effects, and/or mental health outcomes; findings; strengths and limitations; and recommendations for future research, policy and design practice.

Because of the range of study designs and disciplines included, we created a quality assessment matrix for this review including (i) appropriateness of study design 
to the research question, (ii) presence of definitions and operationalization of high-rise residential buildings, and social effects and/or mental health outcomes, (iii) quality of data collection, and (iv) quality of analysis. One reviewer assigned to that paper plus an experienced second reviewer (the same person for each study) evaluated the quality of the studies, scoring each element from 0 to 2 according to the criteria presented in Table 1. Differences were discussed and an agreed score assigned. A quality score, ranging from 0 to 10 , was generated by adding the scores for each element to create a composite indicator. Characteristics and quality of the studies are presented in narrative form, and in total and relative frequencies. Table 2 shows the quality scores for each included study.

\section{Characteristics and quality of articles selected}

23 papers were included in this review. These studies discuss the impacts of house type, floor level, and external / internal spaces intrinsic of high-rise residential buildings on social well-being and/or mental health. Table 3 and Supplementary Material 2 summarize characteristics and key findings of the selected studies. Concerning the year of publication, the earliest article was published in 1974. Ten papers were published recently, from 2010 to 2016, suggesting an increasing interest in this topic.

Most of the research was conducted across the Global North, in high-income countries. The highest number of studies were carried out in the United Kingdom (eight papers), followed by studies from the United States (four papers), South Korea (two papers), Canada (two papers), Netherlands (two papers), Japan (two papers), and Albania, Brazil and Singapore (one apiece).

The mean quality score for the 23 papers was 6 (standard deviation $=1$; quality score ranging from 0 to 10). Nine had a score of 7 or higher, and only four scored less than 5 (Table 2). Only one study used a longitudinal or experimental design. Seven studies did not provide a thorough description of the high-rise residential buildings, whereas only one did not formally operationalise its outcomes (e.g. social well-being and/or mental health outcomes).

Almost all papers were evaluated as adequate or excellent in terms of quality of data collection $(n=20)$ and data analysis $(n=20)$. All papers with a total score of 7 or higher received at least one point in every criterion. The majority of the research designs lacked controls (e.g. random assignment to building types) or information on confounders (e.g. socio-economic status).

In view of the relatively small number of studies that met the inclusion criteria for our systematic review, we did not exclude any study on the grounds of quality but considered the reliability of overall evidence in relation to the studies' quality. It should be noted that apart from the study design, low scores primarily reflect the lack of information provided in the paper and are not necessarily a reflection of the quality of the studies themselves. 

Table 1. Quality assessment criteria.

\begin{tabular}{|c|c|c|c|c|c|}
\hline \multirow[b]{2}{*}{ Score } & \multirow{2}{*}{$\begin{array}{c}\text { Appropriateness of study } \\
\text { design }\end{array}$} & \multicolumn{2}{|c|}{ Definitions and operationalisation } & \multirow{2}{*}{$\begin{array}{l}\text { Quality of data } \\
\text { collection }^{\mathrm{a}}\end{array}$} & \multirow[b]{2}{*}{ Quality of analysis $^{b}$} \\
\hline & & Housing & $\begin{array}{c}\text { Mental health / Social } \\
\text { consequences }\end{array}$ & & \\
\hline 0 & $\begin{array}{l}\text { Unable to answer their } \\
\text { research question }\end{array}$ & No definition of 'high-rise' & $\begin{array}{l}\text { No concepts or } \\
\text { operationalisation described }\end{array}$ & Poor or not described & Poor or not described \\
\hline 1 & Cross-sectional & $\begin{array}{l}\text { Number of storeys OR other } \\
\text { attributes described }\end{array}$ & $\begin{array}{l}\text { Concepts or operationalisation } \\
\text { described }\end{array}$ & Adequate & Adequate \\
\hline 2 & $\begin{array}{l}\text { Longitudinal or randomised } \\
\text { assignment }\end{array}$ & $\begin{array}{l}\text { Number of storeys AND other } \\
\text { attributes described }\end{array}$ & $\begin{array}{l}\text { Validated scale used, if } \\
\text { quantitative data }\end{array}$ & Excellent & Excellent \\
\hline
\end{tabular}

a: Assessed in relation to study type (e.g., quantitative, qualitative, observational, mixed methods, or review), considering factors such as: sampling design, sample size, response rate, training of interviewer, use of validated survey tools for quantitative study; sampling design, training of interviewer, specified type of data collection (e.g., interview, focus groups), procedures to limit bias for qualitative study; literature search terms and databases searched for review.

b: Assessed in relation to study type (e.g., quantitative, qualitative, observational, mixed methods, or review), considering factors such as: descriptive analyses only or adjusting for potential confounding factors for quantitative study; use of formal analysis software or underlying theory for qualitative study. 
Table 2. Quality assessment.

\begin{tabular}{|c|c|c|c|c|c|c|c|}
\hline \multirow[b]{2}{*}{ First author } & \multirow[b]{2}{*}{ Year } & \multirow{2}{*}{$\begin{array}{l}\text { Global } \\
\text { rating }\end{array}$} & \multirow{2}{*}{$\begin{array}{l}\text { Appropriateness of } \\
\text { study design }\end{array}$} & \multicolumn{2}{|c|}{ Definitions and operationalisation } & \multirow{2}{*}{$\begin{array}{l}\text { Quality of data } \\
\text { collection }\end{array}$} & \multirow{2}{*}{$\begin{array}{c}\text { Quality of } \\
\text { analysis }\end{array}$} \\
\hline & & & & Housing & $\begin{array}{c}\text { Mental health / } \\
\text { Social outcomes }\end{array}$ & & \\
\hline Gibson M & 2011 & 8 & 2 & 1 & 1 & 2 & 2 \\
\hline Zaff J & 1998 & 8 & 1 & 2 & 2 & 1 & 2 \\
\hline Angrist S & 1974 & 7 & 1 & 1 & 2 & 1 & 2 \\
\hline Ghosh S & 2014 & 7 & 1 & 2 & 1 & 1 & 2 \\
\hline Kearns A & 2015 & 7 & 1 & 1 & 1 & 2 & 2 \\
\hline Kearns A & 2012 & 7 & 1 & 1 & 1 & 2 & 2 \\
\hline Knipschild P & 1978 & 7 & 1 & 2 & 2 & 1 & 1 \\
\hline Pojani D & 2015 & 7 & 1 & 1 & 1 & 2 & 2 \\
\hline Saito K & 1993 & 7 & 1 & 1 & 2 & 1 & 2 \\
\hline Hannay D & 1981 & 6 & 1 & 1 & 1 & 1 & 2 \\
\hline Hooper D & 1979 & 6 & 2 & 0 & 1 & 2 & 1 \\
\hline Kitchen P & 2012 & 6 & 1 & 0 & 1 & 2 & 2 \\
\hline $\mathrm{LiX}$ & 1994 & 6 & 1 & 1 & 1 & 1 & 2 \\
\hline Masters N & 1989 & 6 & 1 & 2 & 2 & 1 & 0 \\
\hline McCarthy P & 1985 & 6 & 1 & 1 & 2 & 0 & 2 \\
\hline Asgarzadeh M & 2014 & 5 & 1 & 1 & 1 & 0 & 2 \\
\hline Kowaltowski D & 2006 & 5 & 1 & 1 & 1 & 1 & 1 \\
\hline Phoon W & 1976 & 5 & 1 & 1 & 1 & 1 & 1 \\
\hline Quinn N & 2010 & 5 & 1 & 0 & 1 & 2 & 1 \\
\hline Husaini B & 1991 & 4 & 1 & 0 & 2 & 1 & 0 \\
\hline Lee J & 2011 & 4 & 1 & 0 & 1 & 1 & 1 \\
\hline Jung E & 2015 & 3 & 1 & 0 & 0 & 0 & 2 \\
\hline Korte C & 1983 & 3 & 1 & 0 & 1 & 1 & 0 \\
\hline
\end{tabular}




\section{The influence of physical and spatial aspects of high-rise residential buildings on social well-being and mental health}

\subsection{Terminology}

Our review is structured in the following categories: semi-public spaces (e.g. shared entrances, private entrances); floor level (e.g. ground floor); house type (e.g. high-rise residential building); and streetscapes. The key findings related to each of these housing variables are summarized within Table 3, which lists the included studies alphabetically. This section aims to clarify the terms employed in this systematic review.

'High-rise residential building' denotes a physical structure with at least four storeys that necessarily, but not exclusively, contains a number of private residences (also referred as apartments or flats) reached via a shared entrance, stairwell and/or lifts. For the purposes of this systematic review, this terminology also includes mixeduse residential high-rise developments. The upper floor level benchmark varies across the included studies. Saito et al. (1993), Kearns et al. (2012) and Hannay (1981) define the $15^{\text {th }}$, sixth and fifth storey and above as upper floor levels, respectively. Kowaltowski et al. (2006) compares the ground floor with the higher floor levels.

'Semi-public spaces' embrace those shared spaces intrinsic to high-rise residential buildings or other house types (e.g. shared entrances, private entrances). 'Streetscape' is used to refer to all elements (e.g. buildings, urban furniture, sidewalks) that define the appearance of a street.

The overarching category 'social well-being' includes a range of social variables, such as: social contacts, anti-social behaviour, social network, sense of belonging, sense of community, memberships, sense of control, social cohesion, social capital and social support.

'Mental health' embraces both affective outcomes (e.g. quality of life, mood, loneliness) and mental illnesses (e.g. clinical neurosis, depression, schizophrenia) that may be directly (or indirectly) influenced positively or negatively by high-rise living. Although we occasionally use terms that suggest causality, such as "consequences", "outcomes", and "effects" most researchers have investigated "associations" or "relationships". 
Table 3. Characteristics and main findings of the selected studies

\begin{tabular}{|c|c|c|c|c|c|c|}
\hline First author & Year & Country & Context & Exposure & Social well-being & Mental health \\
\hline Angrist S & 1974 & US & Deprived & Living in high-rises vs. other housing types & & Fear $(+)$ \\
\hline \multirow{2}{*}{ Asgarzadeh M } & \multirow{2}{*}{2014} & \multirow{2}{*}{ Japan } & \multirow{2}{*}{$x$} & Views of high-rises & & Oppressiveness (+) \\
\hline & & & & Views of sky and trees in front of high-rises & & Oppressiveness (-) \\
\hline Ghosh S & 2014 & Canada & Deprived & Living in high-rises & Sense of community $(+)$ & \\
\hline \multirow{10}{*}{ Gibson M } & \multirow{10}{*}{2011} & \multirow{10}{*}{ UK } & \multirow{10}{*}{ Deprived } & Living in high-rises vs. other housing types & Sense of control (-) & Well-being (-) \\
\hline & & & & & Sense of control (-) & \\
\hline & & & & & Safety (-) & Well-being (-) \\
\hline & & & & Communal spaces vs. private garden & Privacy (-) & Quality of life (-) \\
\hline & & & & & Antisocial behaviour $(+)$ & Positive mood (-) \\
\hline & & & & & Levels of sociability $(-)$ & \\
\hline & & & & & Sense of control (-) & Quality of life (-) \\
\hline & & & & Shared vs. private entrances & Safety (-) & Positive mood (-) \\
\hline & & & & & Privacy $(-)$ & Stress $(+)$ \\
\hline & & & & Streetscape & Anti-social behaviour (+) & \\
\hline \multirow{2}{*}{ Hannay D } & \multirow{2}{*}{1981} & \multirow{2}{*}{ UK } & \multirow{2}{*}{ Deprived $^{* *}$} & Living in high-rises vs. other housing types & & Mental symptoms (+) \\
\hline & & & & Living upper floors vs. lower floors & & Mental symptoms (+) \\
\hline Hooper D & 1979 & UK & Varied & Living in high-rises vs. other housing types & & Clinical neurosis $(+)$ \\
\hline \multirow{5}{*}{ Husaini B } & \multirow{5}{*}{1991} & \multirow{5}{*}{ US } & \multirow{5}{*}{ Deprived $^{* *}$} & \multirow{5}{*}{ Living in high-rises vs. other housing types } & \multirow{5}{*}{ Social support (-) } & Stress $(+)$ \\
\hline & & & & & & Depression (+) \\
\hline & & & & & & Mental disorder (+) \\
\hline & & & & & & Schizophrenia $(+)$ \\
\hline & & & & & & Simple phobia $(+)$ \\
\hline Jung $E$ & 2015 & South Korea & $x$ & Pedestrian-friendly streetscape & Sense of community $(+)$ & \\
\hline \multirow{8}{*}{ Kearns A } & \multirow{8}{*}{2012} & \multirow{8}{*}{ UK } & \multirow{8}{*}{ Deprived } & & Perception of anti-social behaviour (+) & \\
\hline & & & & & Sense of community (-) & \\
\hline & & & & Living in high-rises vs. other housing types & Cohesion (-) & \\
\hline & & & & & Social contact (-) & \\
\hline & & & & & Social support network (-) & \\
\hline & & & & & Social cohesion $(+)$ & \\
\hline & & & & Living upper floors vs. lower floors & Social contact $(+)$ & \\
\hline & & & & & No social support (-) & \\
\hline
\end{tabular}


Table 3. Characteristics and main findings of the selected studies (continuation).

\begin{tabular}{|c|c|c|c|c|c|c|}
\hline First author & Year & Country & Context & Exposure & Social well-being & Mental health \\
\hline Kearns A & 2015 & UK & Deprived & Living in high-rises vs. other housing types & & Loneliness (o) \\
\hline Kitchen P & 2012 & Canada & $\mathrm{x}$ & Living in high-rises vs. other housing types & Sense of belonging (-) & Mental health (-) \\
\hline Knipschild P & 1978 & The Netherlands & Privileged ${ }^{* *}$ & Living in high-rises vs. other housing types & & $\begin{array}{l}\text { Psychological problems (-) } \\
\text { Sedatives and hypnotics (-) } \\
\text { Psychosomatic problems (o) }\end{array}$ \\
\hline Korte C & 1983 & The Netherlands & $\mathrm{x}$ & Living in high-rises & Social support (-) & \\
\hline \multirow[b]{2}{*}{ Kowaltowski D } & \multirow[b]{2}{*}{2006} & \multirow[b]{2}{*}{ Brazil } & \multirow[b]{2}{*}{ Deprived } & Living in high-rises vs. other housing types & Sense of belonging $(+)$ & \\
\hline & & & & Living upper floors vs. lower floors & $\begin{array}{l}\text { Sense of control }(+) \\
\text { Privacy }(+) \\
\text { Security }(+)\end{array}$ & \\
\hline Lee J & 2011 & South Korea & Privileged & Semi-public spaces in high-rises & & Quality of life (+) \\
\hline LiX & 1994 & $\mathrm{x}$ & Deprived & Living in high-rises vs. other housing types & Risk behaviours (o) & \\
\hline Masters N & 1989 & UK & Deprived & Living in high-rises vs. other housing types & & Depression $(+)$ \\
\hline McCarthy $\mathrm{P}$ & 1985 & UK & Deprived & Living in high-rises vs. other housing types & & Psychological distress (o) \\
\hline \multirow{2}{*}{ Phoon W } & \multirow{2}{*}{1976} & \multirow{2}{*}{ Singapore } & \multirow{2}{*}{ Deprived } & Living in high-rises & Social contacts friends \& relatives (-) & \\
\hline & & & & Corridors in high-rises & Social contacts with neighbours $(+)$ & \\
\hline \multirow{3}{*}{ Pojani D } & \multirow{3}{*}{2015} & \multirow{3}{*}{ Albania } & \multirow{3}{*}{ Privileged } & Living in high-rises vs. other housing types & $\begin{array}{l}\text { Social cohesion (-) } \\
\text { Social network (-) }\end{array}$ & \\
\hline & & & & Dark and narrow staircases & Social network (-) & \\
\hline & & & & Elevators & Social network (-) & \\
\hline Quinn N & 2010 & Scotland & Deprived & Living in high-rises & Social capital $(+)$ & Mental health $(+)$ \\
\hline Saito K & 1993 & Japan & $x$ & Living upper floors vs. lower floors & & Psychological distress (o) \\
\hline Zaff $\mathrm{J}$ & 1998 & US & Deprived & Living in high-rises vs. other housing types & $\begin{array}{l}\text { Sense of community (-) } \\
\text { Membership (-) }\end{array}$ & \\
\hline
\end{tabular}

** $=$ presumably

$X=$ no information

$\mathrm{o}=$ no evidence of association; + = positive association; - = negative association 


\subsection{Semi-public spaces, social well-being and mental health}

\subsubsection{Results}

Of all 23 included studies, two explored the associations between semi-public spaces intrinsic to high-rise buildings and social well-being (Pojani \& Buka, 2015; Phoon et al., 1976) (Table 3). Pojani \& Buka (2015) found that narrow, dark staircases and elevators are spaces likely to inhibit social interactions and, therefore, the expansion of social networks, while Phoon et al. (1976) reported that the large majority of social contacts in high-rises take place in corridors.

Gibson and her colleagues (2011) found associations between semi-public spaces and a range of domains of social well-being which, in turn, were reported to be linked to mental health outcomes (Table 3). These findings reinforce the importance of exploring social well-being as a potentially mediating variable between built environments and mental health.

Gibson et al. (2011) found that communal areas behind high-rises are related to worse social effects (i.e. higher perception of antisocial behaviour, lower sense of control) which, in turn, are linked to poorer mental health outcomes than private gardens of houses. Likewise, shared entrances were reported to be associated with lower sense of control, safety and privacy, which, in turn, were associated with poorer mental health than private entrances intrinsic to houses (Gibson et al., 2011).

Lee (2011) found positive associations between physical attributes of semipublic spaces of high-rise mixed-use housing buildings, which includes community facilities and commercial area, and quality of life (Table 3). The findings of the studies included in this literature review show that semi-public spaces inherent to high-rises are not necessarily bad for social well-being and mental health, but that some physical and spatial configurations are worse than others for social well-being and mental health.

\subsubsection{Discussion and shortcomings}

The finding that narrow, dark staircases and elevators are spaces likely to inhibit the formation of social ties (Pojani \& Buka, 2015) and that corridors accommodate the large majority of social contacts that take place in a high-rise residential building (Phoon et al., 1976) suggests that if social interactions are too short and infrequent, residents may not experience a sense of social support, a necessary condition for the development of more complex domains of social well-being (e.g. social cohesion).

Semi-public spaces intrinsic to high-rise residential buildings (e.g. shared entrances) were associated with worse social effects which, in turn, were associated with poorer mental health outcomes than their equivalent in houses (e.g. private entrances) (Gibson et al., 2011). This finding supports the thesis developed by Newman (1972) that those physical and spatial configurations that inhibit expressions 
of territorial claims and offer fewer opportunities for surveillance usually are problematic:

The problem of unwanted interlopers in housing with shared entrances was a theme that recurred frequently, and was described as causing extreme stress, fear and disturbed sleep. By contrast, private entrances provided respondents with defensible space which permitted them to monitor and control entry to their property. Increases in privacy and security provided by private entrances impacted on affective outcomes such as well-being, quality of life, stress levels and mood through the psychosocial process of control (Gibson et al. 2011, p.565).

The marking of territoriality by personalization, however, does much more than affording the emergence of so called "defensible spaces" (as proposed by Newman, 1972). As a mode of communication (Bentley et al. 1985; Hall, 1966), personalization of spaces also foster a sense of attachment and belonging (Mehta, 2014). In addition, the embellishment of the semi-public spaces also may impact on their maintenance and attractiveness (Mehta, 2014). By placing plants and paintings in front of the main entrance of their apartments, for example, dwellers extend a sense of control and identity to the corridor.

\subsection{Floor level, social well-being and mental health}

\subsubsection{Results}

Two studies reported six associations between floor level and social well-being (Kearns et al., 2012; Kowaltowski et al., 2006) (Table 3). Upper floor levels were consistently associated with better social effects. Kearns et al. (2012) found that certain social outcomes (e.g. social cohesion, social contact) were better higher up the building while Kowaltowski et al. (2006) found that the residential ground floor was potentially problematic due to the lack of control, privacy and safety.

Hannay (1981) found that primary care patients living on the fifth floor or above faced a twofold ratio of mental health symptoms compared with those on lower floors. Saito et al. (1993), on the other hand, reported no association between floor level and psychological distress.

\subsubsection{Discussion and shortcomings}

Figure 3 summarizes the key findings about floor level and social well-being and mental health. Results of the research conducted by Kearns et al. (2012) and Kowaltowski et al. (2006) reinforce each other and provide support to the hypothesis that residents living on higher levels tend to be insulated from the negative effects lower down the building (e.g. lack of privacy). In the view of the authors, those semipublic spaces intrinsic to high-rise residential buildings identified as problematic (Newman, 1972) and situated on the ground floor (e.g. communal area and shared entrances) may explain, at least partially, why the lower floor levels are associated with worse social effects. 
If we take social outcomes as mediators, better mental health outcomes would be expected among those living higher up. However, of the two studies that examined associations between floor level and mental illness (Hannay,1981; Saito et al.,1993) a positive association was reported by one and no association by the other. The former unexpected finding may be explained by self-selection bias, i.e. people with mental problems may choose to live on higher floor levels, a methodological problem previously raised by Evans (2003).

The absence of association between floor level and mental health reported by Saito et al. (1983), on the other hand, may be elucidated on the basis that the interrelationship between floor level and mental health may also be strongly influenced by culture. The divergent results may also be explained on the basis that the high-rise residential buildings investigated presented different types of floor levels.

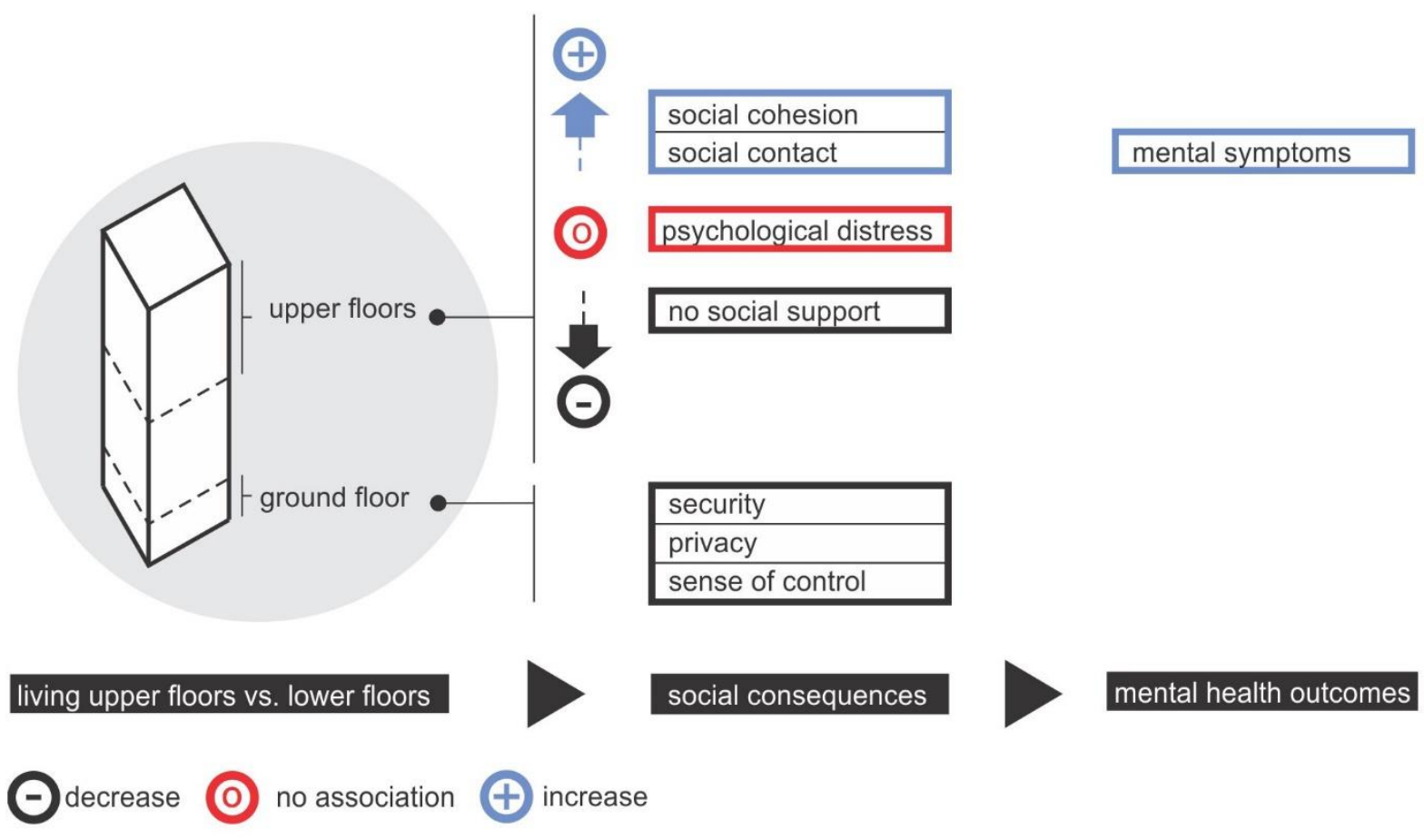

Fig. 3. Key findings (floor level)

\subsection{House type, social well-being and mental health}

\subsubsection{Results}

All four studies that investigated the associations between high-rise residential building and different domains of social well-being found significant associations between these variables (Ghosh, 2014; Korte \& Huismans,1983; Phoon et al., 1976; Quinn \& Biggs, 2010). The findings show that high-rise residential buildings, even in deprived areas, are not necessarily associated with poor social well-being. Quinn and Biggs (2010), for example, reported a significant association between high-rise residential building and social capital which, in turn, was related to positive mental health outcomes in an area of high deprivation in Glasgow. 
A total of 13 associations and one nonsignificant association between living in high-rise versus alternative housing types and different domains of social well-being were tabulated (Table 3). Of all associations, the large majority (12) shows high-rise residential buildings to be associated with worse social outcomes than alternative housing types.

Focusing on the divergent findings, Kowaltowski et al. (2006) reported that apartment dwellers tend to experience a stronger sense of belonging than those who live in houses and explained that house owners in the context of low-income housing development in the region of Campinas (Brazil) value very much their individual lot. $\mathrm{Li}$ et al. (1994) found no association between house type and adolescent risk behaviour (e.g. drug trafficking and substance abuse). The evidence shows that risk behaviours are actually associated with parental monitoring, social support and perceived risk exposure (Li et al., 1994).

Two of the included studies examined the associations between living in highrise residential buildings versus alternative housing types and specific sub-domains of social well-being as pathways to mental health (Gibson et al., 2011; Kitchen et al., 2012). These studies found high-rise residential buildings to be associated with poorer social well-being and mental health than alternative housing types. Kitchen et al. (2012) found a significant association between sense of belonging and mental health, while Gibson et al. (2011) reported that sense of control mediates mental health. Evidence, therefore, confirms the importance of taking into account different domains of social well-being as possible explanatory mechanisms for mental health.

Overall, the results of the included papers indicate that house type and mental health are associated. A total of 13 statistically significant associations and three nonsignificant associations between housing type and mental health were mapped (Table 3). Based on the results obtained by the studies included in this review, the large majority (11) of associations were in the expected direction: high-rise residential buildings were (directly or indirectly) associated with worse mental health outcomes than alternative housing types (Table 3).

The divergent results came from McCarthy (1985) and Kearns et al. (2015), who reported no association between housing type and psychological distress and loneliness, respectively. They found that mental illness correlated less strongly with the type of housing rather than with where it was located.

To increase the generalizability of these conflicting findings, however, future empirical research needs to select cases that are better distributed geographically and take into account the potential influence of contextual factors. Knipschild (1978) reported that dwellers of high-rise buildings tended to have fewer psychological problems and use fewer sedatives and hypnotics than those people living in houses, while no differences in psychosomatic problems were found. 
According to Knipschild (1978), some possible explanations for these unexpected findings are: (i) unlike previous studies, the apartments studied were better constructed than the houses, (ii) people mistakenly may say that their problems are caused by their living conditions rather than other factors (e.g. their families situation), (iii) people who live in apartments, for some reason, may be less likely to see a doctor for mental problems, although they may actually occur, and (iv) most of the apartment dwellers did not live there for more than five years and it is possible that harmful health effects may occur after longer periods of exposure.

\subsubsection{Discussion and shortcomings}

Overall, the evidence shows that although high-rise residential buildings, even those located in deprived contexts, are not necessarily associated with poor social well-being and mental health, high-rise residential buildings are related to worse social effects and mental health outcomes than alternative types of housing (Fig. 4).

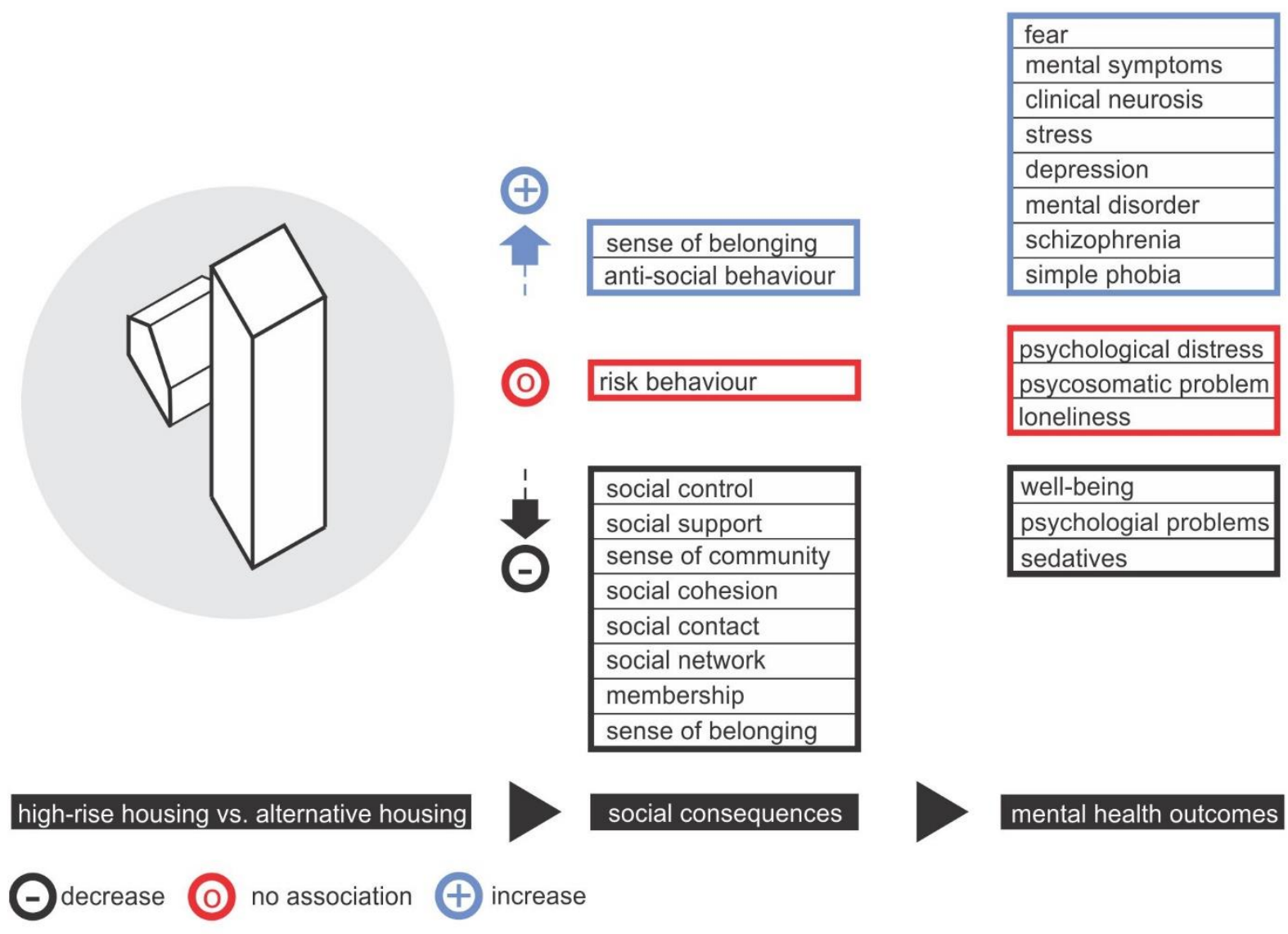

Fig. 4. Key findings (housing type)

It is important to bear in mind, however, that of all studies that analysed highrise residential buildings versus alternative dwellings, the majority included dwellers that lived on lower floor levels. In the view of the authors, the inclusion of this group is problematic since these dwellers have to deal with negative social effects commonly associated with shared entrances and other semi-public spaces located in the ground floor. 
Based on the general shortage of empirical research, unbalanced geographical distribution of the cases studied as well as the methodological inadequacies (e.g. research designs lacked adjustment for confounders), we offer an alternative hypothesis to explain why high-rise residential buildings were associated with worse social effects and mental health outcomes than other types of buildings.

We note first, that the majority of papers included in this review report results of research carried out in North America and Europe, where a large number of high-rise residential buildings were developed by the public sector after the Second World War in deprived areas (Verhaeghe et al., 2016). Secondly, from the 1970s, high-rise residential buildings in these continents became associated with a negative image (Pereira, 2017). Bearing these two facts in mind, it is plausible to hypothese that stigmatization might explain the negative social effects and, in turn, the mental illness associated with this type of house in the context of North America and Europe (Evans et al., 2003).

\subsection{Streetscape, social well-being and mental health}

\subsubsection{Results}

Of the 23 included studies, three examined the social effects and mental health outcomes associated with streetscapes shaped by high-rise residential buildings (Gibson et al., 2011; Jung et al., 2015; Asgarzadeh, 2014) (Table 3). Gibson et al. (2011) found that streetscapes framed by high-rises are a better predictor of anti-social behaviour (or perception of anti-social behaviour) than those framed by houses.

Jung et al. (2015) reported that pedestrian-friendly streetscapes enclosed by high-rises provide a stronger sense of community that those that are car-oriented. Asgarzadeh (2014) reported that opportunities to view sky and trees in front of highrises tend to attenuate the sense of oppressiveness associated with streetscapes walled by this building type.

\subsubsection{Discussion and shortcomings}

The results of the studies in this review suggest that streetscapes intrinsic to high-rises are associated with lesser sense of control and increased perception of antisocial behaviour that those enclosed by other house types (Gibson et al., 2011). This is to be expected, as they tend to offer lower external visibility compared with streetscapes associated with other buildings types.

The findings of the research conducted by Jung et al. (2015) and Asgarzadeh (2014) show that streetscapes shaped by high-rises are not necessarily associated with negative social effects or mental health outcomes. The evidence indicates that the urban design of streetscapes does matters to public health, or rather, the design and arrangement of high-rise residential buildings and some micro-scale physical elements along the streets (e.g. trees) are likely to influence social well-being and mental health. 


\section{General discussion and shortcomings}

The methodological inadequacies mapped by Evans et al. (2003) more than 15 years ago still feature in the large majority of the empirical studies included in this systematic literature review. First, no standard ontology of terms and research approaches exists: different studies adopt different conceptualizations, operationalisations and scales to measure what appears to be the same construct.

In addition, the research design and analysis of the large majority of the included researches did not take into account moderators (e.g. personal variables), mediators (e.g. social control) nor confounders (e.g. socio-economic status) (Supplementary Material 2). Additional research on how different domains of social well-being mediate the linkage between high-rise and mental health, as previously pointed out by Evans et al. (2003), is still on needed.

This systematic review has some limitations. Although it included documents available in six major databases, we could not capture all potential valuable evidence from the grey literature. In addition, we did not scan the reference lists of the included papers. Therefore, there is a possibility that some publications may have been overlooked.

Thus, more rigorous research is needed. Although causality cannot be assumed because almost all the studies are cross-sectional, this review reveals that although there is no consensus on how different housing variables impact on social well-being and mental health, they are inter-related. The results of the included studies also show that although living in high-rise residential buildings is not necessarily bad, it tends to trigger worse social effects and mental health outcomes than other types of housing (e.g. low-rise residential buildings). As part of an attempt to provide a framework for future research, it is important to highlight that evidence also shows that other environmental aspects (e.g. noise) can have a direct effect on the residents' mental health (Evans, 2003) (Fig. 5).

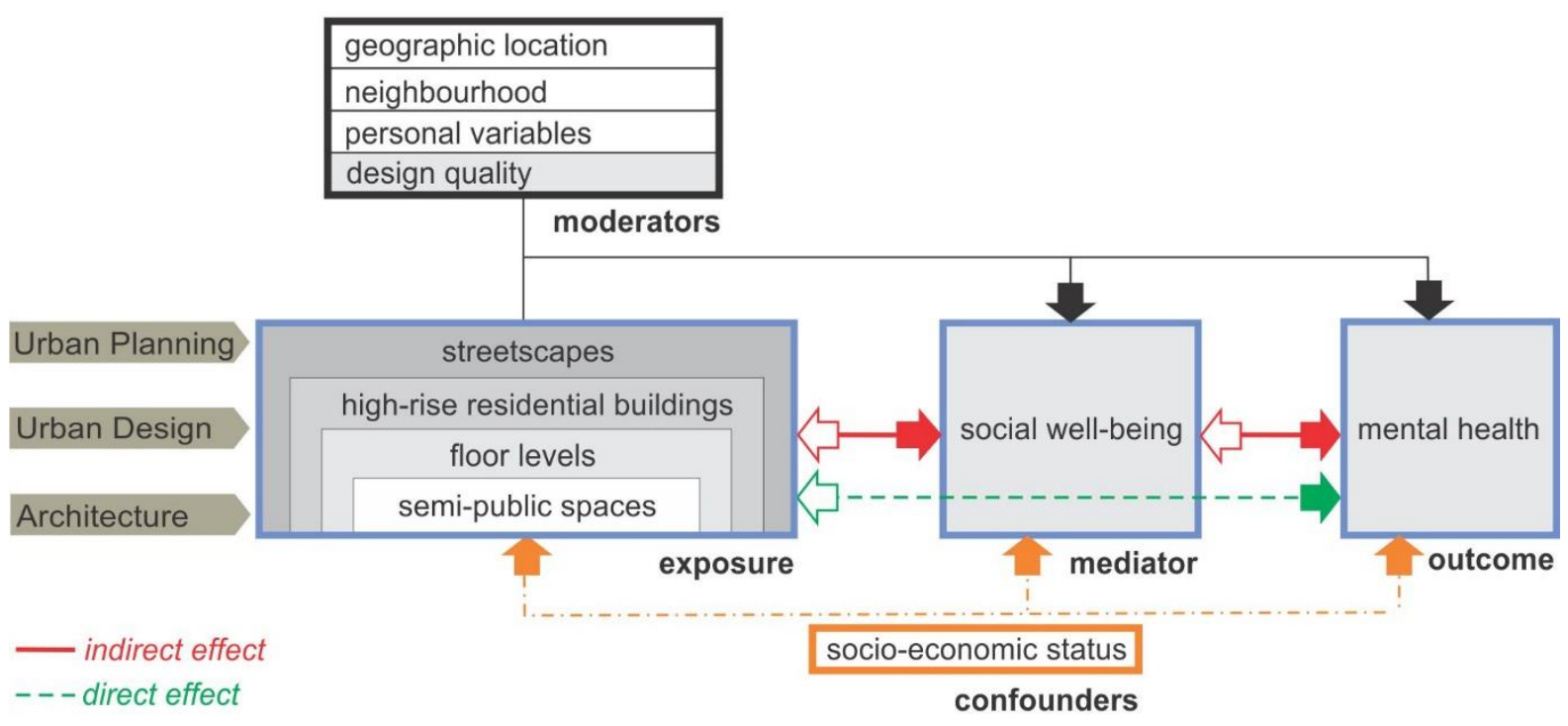

Fig. 5. Key conceptual issues. 
Our review shows a need for a deeper understanding of how planning and the quality of the urban design and architectural solutions moderate the harmful effects associated with high-rise residential buildings (Fig. 5). In this regards, the included studies explored the social effects and mental health outcomes associated with "generic" high-rise residential buildings. To deeper our understanding of the processes underlying the connections between housing variables, social well-being and mental health, the authors, building on Evans et al. (2003) previous critical review, suggest a different focus and diagnosis.

Perhaps living in high-rise residential buildings is associated with worse social effects and mental health outcomes due to the poorer quality of their semi-public spaces (e.g. shared entrances, communal spaces, corridors). From the results of the studies selected, it is plausible to hypothesise that design quality moderates the interrelationships between housing and social well-being which, in turn, influences mental health.

None of the research included investigated, for example, how different types of ground floor level (e.g. with vs. without pilotis), corridors (e.g. with vs. without nice panoramic views) or perceptual qualities (e.g. human scale, legibility, permeability) may moderate the inter-relationship between high-rise residential buildings, social well-being and mental health. These gaps in the literature reinforce the need for interdisciplinary research, since designers can contribute towards the operationalization of these variables.

A further strength of this review has been its cross-disciplinary nature. Working across disciplines challenged the authors' assumptions and outlooks, leading to a more holistic appraisal of the available literature. For example, the architects noted the lack of definition of 'high-rise' in most of the papers reviewed, while those with epidemiology expertise were better able to provide critiques of the study methods and the extent to which each study was capable of answering its own research question(s). All the shortcoming and gaps revealed by this literature review, however, clearly indicate opportunities for further research.

The conclusions of this review may not be applicable to all cities worldwide for three main reasons: (1) the definitions of high-rise housing as well as of the myriad of concepts classified as "social well-being" and "mental health" are culturally bound; (2) many studies examined the social effects and mental health outcomes of high-rise residential building on specific social groups, such as the aged; and (3) cultural attitudes and norms regarding high-rise dwelling vary substantially depending on country and context.

\section{Avenues for future research agenda on impacts of high-rise residential buildings on social well-being and mental health}

We see a number of prospects for research into the positive and negative effects of high-rise residential buildings on social well-being and mental health and how planning, urban design and architectural decisions influence these. 
1. The complexity of the topic requires more inter- and trans-disciplinary work. Collaboration between different disciplines, such as architecture, psychology, urban planning, urban design, public health, epidemiology, sociology, human geography and ecology, holds the promise of offering new perspectives. Learning and adapting methods across disciplines are expected to increase knowledge and help policy makers, planners, urban designers and architects to take decisions that are more inclusive and evidence-based.

2. It is important that future studies bring clearer definitions and operationalisations of high-rise housing, social effects and mental health outcomes. As far as the definitions of "high-rise" and "higher floor level" are concerned, the adoption of parameters based on our sensory apparatus may be more universally accepted. Taking into account how human senses influence perception and behaviour (Hall, 1966), four storeys can be chosen as a threshold, since above 44 feet (13.5 metres) people on the ground cannot be recognized or contacted (Gehl, 2010). Once a more standardized ontology of terms and research approaches exists, a meta-analysis approach may provide an invaluable synthesis.

3. Accepting that personal variables are moderators, it is likely that different groups experience differently some specific physical-spatial configurations in high-rise buildings. Thus, it should be addressed systematically whether the outcomes identified are mostly due to design of the high-rise residential buildings or to social class, life cycle stage, gender, or other moderators.

4. The large majority of papers assessed in this review provide evidence from studies carried out in high-income countries in the Northern hemisphere. An urgent shift of scientific focus to low- and middle-income countries, where most of the urban population growth is concentrated, is needed. This will enable researchers to discover whether the negative outcomes frequently associated with living in high-rise buildings are cross-cultural or related to a specific context.

5. Future research needs to take into account multiple confounding variables (e.g. socio-cultural-economic position), moderators (e.g. neighbourhood quality and personal variables), and mediators (e.g. social support and social control) to deepen our understanding of the potential roles of urban design and architectural solutions on enhancing social well-being and mental health of those who live in high-rise residential buildings.

6. This literature review reveals that there is a need to carry out studies on how highrise housing may yield positive mental health outcomes.

\section{Conclusions}

The findings of this literature review call for a re-examination of housing policies from a multidisciplinary perspective that takes into account public health concerns together with more empirical research to guide evidence-informed decisions. More needs to be known - and the evidence put into practice - of how the design of high- 
rise residential buildings can influence social relations and, in turn, positive mental health in cities across the globe, not the least for vulnerable population groups (e.g. low-income communities and the elderly).

In addition, the evidence, although not consistent, tends to support the imposition of height limits by planning authorities in contexts where higher levels are associated with poorer mental health, as well as the architectural design of spacious, attractive and naturally well-lit semi-public spaces (e.g. corridors and shared entrances) that facilitate personalization and support social interactions. From this review, it can also be suggested that the design of the interfaces between the private and semi-public (or public) spaces should afford inter-visibility to enhance the dwellers sense of control. 


\section{References}

Al-Kodmany, K. (2018). The Sustainability of Tall Building Developments: A Conceptual Framework. Buildings, 8 (7), 1-31.

Angrist, S.S. (1974). Dimensions of well-being in public housing families. Environ. Behav., 6, 495-516.

Asgarzadeh, M., et al. (2014). Investigating oppressiveness and spaciousness in relation to building, trees, sky and ground surface: A study in Tokyo. Landscape and urban planning, 131, 36-41.

Bentley, I., et al. (1985). Responsive environments: a manual for designers. London: Architectural Press.

Blair, A., et al. (2014). How do neighborhoods affect depression outcomes? A realistic review and a call for the examination of causal pathways. Social Psychiatry and Psychiatric Epidemiology, 49, 873-887.

Clark, C., et al. (2007). A systematic review of the evidence on the effect of the built and physical environment on mental health. Journal of Public Mental Health, 6, 14-27. doi:10.1108/17465729200700011

CTBUH. (2019). Tall buildings in numbers. CTBUH Journal, issue 1, 48-49. Available from: $<$ http://global.ctbuh.org/resources/papers/4045-Journal2019 Issuel TBIN.pdf> (Accessed 12 April 2019).

Diez, R. A. V., \& Mair, C. (2010). Neighborhoods and health. Annals of the New York Academy of Sciences, 1186, 125-145.

Evans, G. W., (2003). The built environment and mental health. Journal of Urban Health, 80 (4), 536-555.

Evans, G. W., Well, N. M., \& Moch, A. (2003). Housing and mental health: a review of the evidence and a methodological and conceptual critique. Journal of Social Issues, 59 (3), 475-500.

Gehl, J. (2010). Cities for people. London: Island Press.

Ghosh, S. (2014). Everyday lives in vertical neighbourhoods: exploring Bangladeshi residential spaces in Toronto's inner suburbs. International Journal of Urban and Regional Research, 38 (6), 2008 - 2024.

Gibson, M., et al. (2011). Understanding the Psychosocial Impacts of Housing Type: Qualitative Evidence from a Housing and Regeneration Intervention. Housing studies,26 (4), 555-73.

Gong, Y., et al. (2016). A systematic review of the relationship between objective measurements of the urban environment and psychological distress. Environment International, 96, 48-57.

Hall, E. T. (1966). The hidden dimension. Garden City, N. Y.: Doubleday.

Hannay, D. R. (1981). Mental health and high flats. Journal of Chronic Diseases, 34, 431432.

Hashemi, F., et al. (2016). Monitoring Social Well-Being in Iran. Social Indicators Research 129(1) 1-12.

Helleman, G., \& Wassenberg, F. (2004). The renewal of what was tomorrow's idealistic city. Amsterdam's Bijlmermeer high-rise. Cities, 21, 3-17.

Hooper, D., \& Ineichen, B. (1979). Adjustment to moving: a follow-up study of the mental health of young families in new housing. 163-68. 
Howden-Chapman, P., Roebbel, N., \& Chisholm, E. (2017). Setting housing standards to improve global health. International Journal of Environment Research and Public Health,14, 1542.

Husaini, B., Moore, S., \& Castor, R. (2008). Social and psychological well-being of black elderly living in high-rises for the elderly. Journal of Gerontological Social Work, 16, 5778.

Julien, D., et al. (2012). Neighborhood characteristics and depressive mood among older adults: An integrative review. International Psychogeriatrics, 24, 1207-11225.

Jung, E., Lee, J. \& Kim, K. (2015). The Relationship Between Pedestrian environments and Sense of Community in Apartment Complexes in Seoul, Korea. Journal of Asian Architecture and Building Engineering, 14 (2), 411-18.

Kearns, A., et al. (2012). 'Living the high life'? Residential, social and psychosocial outcomes for high-rise occupants in a deprived context. Housing Studies, 27 (1), 97-126.

Kearns, A., Whitley, E., \& Ellaway, A. (2015). Lonesome town: Is loneliness associated with the residential environment, including housing and neighbourhood factors? Journal of community psychology, 43 (7), 849-67.

Keyes, M. C. L. (1998). Social well-being. Social Psychology Quarterly, 61 (2), 121-140.

Kitchen, P., Williams, A., \& Chowhan, J. (2012). Sense of community belonging and health in Canada: a regional analysis. Social Indicators Research, 107 (1), 103-26.

Knipschild P. (1978). The effect of living in flats on mental health. A general practice survey. Int Arch Occup Environ Health, 41, 207-15.

Korte C., \& Huismans S. (1983). Sources of assistance among residents of a Dutch highrise development. Am J Community Psychol., 11, 751-755.

Kowaltowski, D. C. C. K., et al. (2006). Quality of life and sustainability issues as seen by the population of low-income housing in the region of Campinas, Brazil. Habitat International, 30, 1100-114.

Lee, J. (2011). Quality of life and semipublic spaces in high-rise mixed-use housing complexes in South Korea. Journal of Asian Architecture and Building Enginieering, 10 (1), 149-156.

$\mathrm{Li}, \mathrm{X}$. et al. (1994). Risk behavior and perception among youths residing in urban public housing developments. Bulletin of the New York Academy of Medicine, 71 (2), 252-266.

Liberati A., et al. (2009). The PRISMA statement for reporting systematic reviews and metaanalyses of studies that evaluate health care interventions: explanation and elaboration. PLoS Med, 6(7), e1000100.

Litman, T. (2015). Analysis of public policies that unintentionally encourage and subsidize urban sprawl, New Climate Economy, NCE Cities Paper 04, London: VTPI and LSE Cities.

Mair, C., Diez Roux, A. V., \& Galea, S. (2008). Are neighbourhood characteristics associated with depressive symptoms? A review of evidence. Journal of Epidemiology and Community Health, 62, 940-946.

Masters, N., \& Birtchenell, J. (1989). Is living in a slab block depressing? Europe PMC, 233 (1468), 664-666.

Mazumdar, S., et al. (2017). The Built Environment and Social Capital: A Systematic Review. Environment and Behavior 50(2) 119-158.

Mehta, V. (2014). The street: a quintessential social public space. Oxon: Routledge.

McCarthy P., et al. (1985). Housing type, housing location and mental health. Soc. Psychiatry., 20, 125-130. 
Moore, T. H. M., et al. (2018). The effects of changes to the built environment on the mental health and well-being of adults: Systematic review. Health \& Place 53 237-257.

Mueller, D. P. (1981). The curent status of urban-rural differences in psychiatric disorder: An emerging trend for depression. The Journal of Nervous and Mental Disease, 169, 1827.

Newman, O. (1972). Defensible space: people and design in the violent city. London: Architectural Press.

Pereira, S. M. (2017). Mass housing in Lisbon: sometimes it works. Journal of Housing and the Built Environment 32(3) 513-532.

Phoon, W. D., et al. (1976). A preliminary study of the health of a population staying in apartments of varying sizes. Singapore Annals of Tropical Medicine and Parasitology, 70 (2), 232-46.

Pojani, D., \& Buka, M. (2015). From camaraderie to detachment: The effect of changing built environment forms on neighborhood relations in a post-communist context. Cities, 49, 66-75.

Quinn, N., \& Biggs, H. (2010). Creating partnerships to improve community mental health and well-being in an area of high deprivation: Lessons from a study with high-rise flat residents in east Glasgow. Journal of Public Mental Health, 9 (4), 16-21.

Rautio, N., et al. (2017). Living environment and its relationship to depressive mood: A systematic review. International Journal of Social Psychiatry 64(1) 92-103.

Renalds, A., Smith, T., \& Hale, P. (2010). A systematic review of built environment and health. Family \& Community Health, 33, 68-78.

Saito, K. et al. (1993). Housing factors and perceived health status among Japanese women living in aggregated dwelling units. International Journal of Health Services, 23, 541554.

Tricco, A. C., et al. (2018). PRISMA extension for scoping reviews (PRISMA-ScR): checklist and explanation. Ann Intern Med, 169 (7), 467-473. doi: 10.7326/M18-0850.

Truong, K. D., \& Ma, S. (2006). A systematic review of relations between neighborhoods and mental health. The Journal of Mental Health Policy and Economics, 9, 137-154.

United Nations, 2018. Sustainable Development Goals. Goal 3: Good Health. Available from: <https://www.un.org/sustainabledevelopment/blog/2018/05/mental-healthneglected-issue-but-key-to-achieving-global-goals-say-un-chiefs/> (Acessed 26 March 2019).

Verhaeghe, P-P., Coenen A., \& Putte B. V. (2016). Is living in a high-rise building bad for your self-rated health? Journal of Urban Health 93, 884-898.

Whiteford, H. A., et al. (2015). The global burden of mental, neurological and substance use disorders: an analysis from the global burden of disease study 2010. PLOS ONE, 10 (2) e0116820.

WHO. (2007). Strengthening mental health promotion. Geneva, World Health Organization (Fact sheet, No. 220).

WHO. (2014). Basic documents. $48^{\text {th }}$ Edition. Geneva, World Health Organization:1.

Zaff, J., \& Devlin, S. (1998). Sense of community in housing for the elderly. Journal of Community Psychology, 26, 381-398. 